\title{
A SUBSTITUTE FOR BUTTERMILK IN THE TREATMENT OF DIGESTIVE DISORDERS DURING INFANCY
}

BY

\author{
KENNETH H. TALLERMAN, M.C., M.D., M.R.C.P. \\ From the Children's Department, London Hospital.
}

In the treatment of digestive disturbances in infancy, especially in acute gastro-enteritis, acid milk mixtures have been used with success for some considerable time. Buttermilk was first used empirically in Holland, with very good effect, and was then adopted elsewhere abroad. At the present time the use of buttermilk, Finkelstein's Eiweissmilch, or concentrated protein milk, can be regarded as the usual routine treatment in acute gastro-enteritis, both on the continent and in America. Protein milk mixtures are, of course, acid milks, consisting of cow's milk curds mixed with buttermilk, or with equal parts of buttermilk and water.

Faber ( ${ }^{1}$ ) and Levine ( ${ }^{2}$ ) have both recently written excellent reviews concerning acid milk mixtures and their use in infant feeding. It is, however, still impossible to give an exact reason why such mixtures prove beneficial. Marriott and Davidson $\left(^{3}\right)$ believe that the reduction of the buffer value of the milk itself, which is brought about in acid milks, is chiefly responsible for their good effect, as it allows gastric digestion to be accomplished more easily. Since the secretion of hydrochloric acid in the stomach is decreased in infants suffering from gastro-intestinal disturbances, this is obviously a point of importance. Schiff and Mosse $\left({ }^{4}\right)$, however, doubt this explanation of the efficacy of these mixtures, and after an exhaustive and critical review of all the data, together with the results of their own experiments, frankly confess that they are unable to assign any one particular reason for their good effect. Györgi suggested that perhaps the lactate ion itself might be the responsible factor in the case of milks soured by lactic acid, but Brahdy $\left(^{5}\right)$ has been unable to find evidence of this.

It is possible that in the percentage composition of the mixtures themselves lies the explanation of their value. It has, however been generally considered that sweet milk mixtures of similar percentage composition do not achieve such good results.

If it be conceded that an acid milk mixture of the type above referred to is the food of choice in gastro-enteritis or in digestive disturbances, then it is a matter of importance, especially in hospital out-patient practice, to be able to employ a mixture of this sort which is easy of preparation or readily obtained, and which is cheap.

Discussion of a Buttermilk Substitute.-Fresh buttermilk itself is not easily obtained in this country. Its preparation by skimming or centrifuging cow's milk and subsequently inoculating this with Bacillus Bulgaricus, is not usually feasible in out-patient practice, any more than is the preparation of 
protein milk. In any case, neither of these preparations can be arranged for by the out-patient mother herself. There exist dried powder preparations of both protein milk and buttermilk, but although this facilitates matters, the expense of such proprietary preparations puts them beyond the scope of the class with which we are dealing.

There is left the possibility of using ordinary skimmed cow's milk to which lactic acid has been added, such as is employed in cases of acute gastroenteritis by Marriott. Although this may be properly prepared in certain. cases, it presents difficulties in the majority of homes in this country, where ice is an unknown luxury. That is to say, the acid is poured into milk insufficiently cooled, and the formation of large tough curds results. In addition to this objection, the milk itself, unless kept properly covered and coming from a reliable source, will only be contaminated and augment the existing enteritis.

To get over these difficulties it was thought that skimmed milk powder prepared by the addition of water to which lactic acid (B.P. 75 per cent.), had been previously added, would effectually achieve the desired results. The milk powder is cheap, relatively sterile, and the addition of lactic acid to the water necessary to reconstitute such a milk so easy as to be virtually foolproof. Numerous experiments have shown that the lactic acid in the proportion of a drachm to the pint ( $0 \cdot 7$ per cent.) can be added to the water required for admixture with the milk powder, and this brought to the boil and poured on the milk powder while stirring, without causing any more than the finest flocculent curd, all of which will easily pass through the teat of a bottle. It has also been found that no further clotting takes place in this mixture on the addition of rennin.

I first used this type of preparation in 1925 and subsequently Dr.Hamilton* has employed it in certain cases of digestive disorder with success. Powers $\left(^{6}\right)$ has recently stated that he has used a similar mixture in cases of acute gastroenteritis with beneficial results.

Properties of the Acid Dried Skimmed Milk Mixture.-If a preparation so cheap and so easy to prepare has properties similar to buttermilk, there can be no reason why it should not be employed under similar conditions.

The percentage composition of buttermilk varies to a slight extent, but the following two arialyses may be taken as representative :

\begin{tabular}{llll|c|c}
\hline & & & & $\begin{array}{c}\text { Veith } \\
(\text { quoted by } \\
\text { Thomson( }\end{array}$ & Finkelstein( $\left.{ }^{8}\right)$ \\
\hline Protein $\ldots$ & $\ldots$ & $\ldots$ & $\ldots$ & $3 \cdot 6 \%$ & $2 \cdot 6 \%$ \\
Fat $\quad \ldots$ & $\ldots$ & $\ldots$ & $\ldots$ & $0 \cdot 5 \%$ & $0 \cdot 75 \%$ \\
Lactose & $\ldots$ & $\ldots$ & $\ldots$ & $4 \cdot 6 \%$ & $3 \cdot 25 \%$ \\
\hline
\end{tabular}

* Personal communication from Dr. C. K. J. Hamilton. 
We may average these figures and take the following as the percentage composition :-

$$
\begin{aligned}
& \begin{array}{llllllll}
\text { Protein } \ldots & \ldots & \ldots & \ldots & \ldots & \ldots & \ldots & 3 \cdot 2 \%
\end{array} \\
& \begin{array}{lllllllll}
\text { Fat } & \ldots & \ldots & \ldots & \ldots & \ldots & \ldots & \ldots & 0.6 \%
\end{array} \\
& \begin{array}{llllllll}
\text { Lactose } & \ldots & \ldots & \ldots & \ldots & \ldots & \ldots & 3.9 \%
\end{array}
\end{aligned}
$$

The salt content may be regarded as 0.75 per cent., and the calory value is equal to ten calories per ounce.

Two well-known firms provide skimmed milk powders, which when reconstituted by the addition of water in the proportion of one part of powder to ten parts of water have, according to their analyses, the following percentage compositions :-

$\begin{array}{llllll}\text { Protein } & \ldots & \ldots & 3 \cdot 5 \% & \text { B } & \text { Average. } \\ \text { Fat ... } & \ldots & \ldots & 0 \cdot 1 \% & 0 \cdot 07 \% & 3 \cdot 4 \% \\ \text { Lactose } & \ldots & \ldots & 5 \cdot 2 \% & 4 \cdot 5 \% & 0 \cdot 08 \% \\ \text { Ash ... } & \ldots & \ldots & 0 \cdot 8 \% & 0 \cdot 7 \% & 0.8 \% \\ \end{array}$

The calory value of these is equal to approximately 10 calories per ounce.

If, as is the almost universal rule, the mother measures out the feeds by means of a teaspoon, a slightly different percentage composition will result. It has been found experimentally that two level teaspoonfuls of skimmeri milk powder are of such weight that when added to an ounce of water a dilution of one part of powder to nine parts of water will result. This makes a ten per cent. increase in the above figures. Taking this into account, the difference in round numbers to be noted between the percentage composition of buttermilk and skimmed milk powder, is that the latter contains 1.5 per cent. more lactose and 0.5 per cent. less fat.

In the treatment of acute gastro-enteritis the lower fat content can be looked upon as an advantage. The slightly increased percentage of lactose present cannot be regarded as seriously disadvantageous. In the first place, the addition of $1 \frac{1}{2}-3$ per cent. of carbohydrate is nearly always prescribed with buttermilk itself, when it is employed. Secondly, the lactose content of the skimmed milk powder is less than 1 per cent. higher than the lactose content of breast milk which, when skimmed, is above all others, the food of choice in acute gastro-enteritis. There seems no good evidence that lactose itself in the amount present is liable to cause any harm.

The hydrogen ion concentration and buffer value of this mixture are the two other properties calling for description, and comparison with those of buttermilk.

Experiments to Determine the Hydrogen Ion Concentration and Buffer Value of these Preparations.-In order to compare these properties in the case of buttermilk and the acid dried skimmed milk, determinations of the hydrogen ion concentration and titration curves were carried out with both.

Dried skimmed milk was made up in the usual way by the addition of water, to which, however, lactic acid had been added in the proportion of 
$0 \cdot 7$ per cent. of the mixture. This was centrifuged, and 5 c.c. of the supernatant fluid was pipetted off, placed in collodion sacs and dialysed against 0.85 per cent. $\mathrm{CO}_{2}$-free saline. The hydrogen ion concentration of the dialysate was estimated colorimetrically by Gillespie's $\operatorname{method}\left({ }^{9}\right)\left({ }^{10}\right)$. For comparative work this method is as accurate as desired. Whether the skimmed milk was made up in the proportion of one part of powder to ten parts of water, or in the proportion of one part powder to nine of water (two level teaspoonsful to the ounce), no apparent difference in the hydrogen ion concentration resulted, and therefore the readings obtained in these two dilutions have been considered together. In a series of fourteen experiments carried out with the above mixture, the following results were obtained:

In 1 expt., H.-ion concentration was equal to $p \mathbf{H ~} \mathbf{4 \cdot 4}$

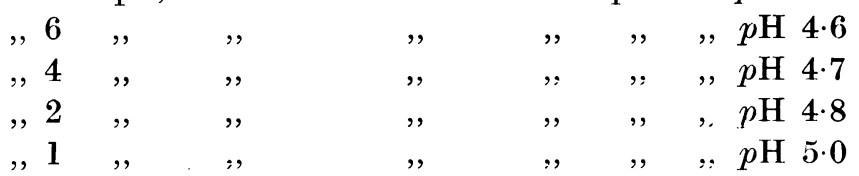

Excluding the two extreme values, an average $p \mathrm{H}$ of $4 \cdot 7$ was obtained in twelve experiments. The figures were remarkably constant and in no case did the duplicate estimates vary by more than $0 \cdot 1$, and in the majority of experiments they were identical.

For comparison, similar experiments were carried out with fresh buttermilk and centrifuged cow's milk soured by the addition of Bacillus Bulgaricus. The hydrogen ion concentration of both these preparations proved to be similar, and the results are therefore considered together. The average reading of five experiments gave a value of $p \mathrm{H} \mathrm{4.5}$, the extreme values differing by $0.2 p \mathrm{H}$.

From the above experiments it appears that the hydrogen ion concentration of buttermilk, and of the mixture of lactic acid dried skimmed milk are for practical purposes the same.

In order to investigate the buffer value, titration curves were carried out and the results are given below :

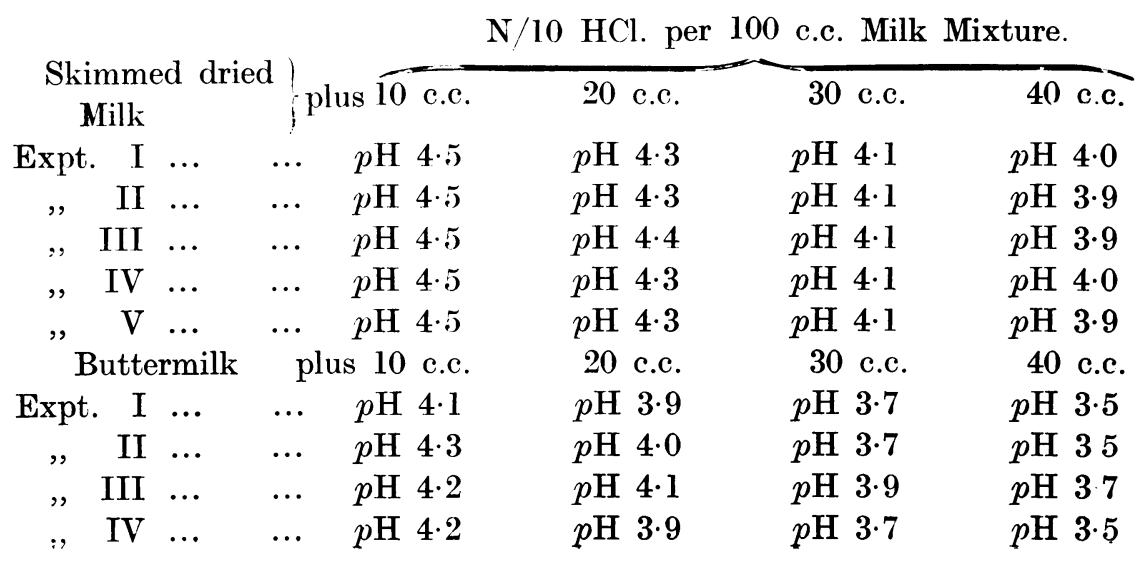


Figure 1 shows these results in the form of a graph made by averaging the results of all the experiments in each series. It will be observed that although the readings obtained in experiments with buttermilk are slightly more acid than is the case when the acid-dried skimmed milk mixture was investigated, the buffer values in both sets of curves are approximately the same.

Fig. 1.

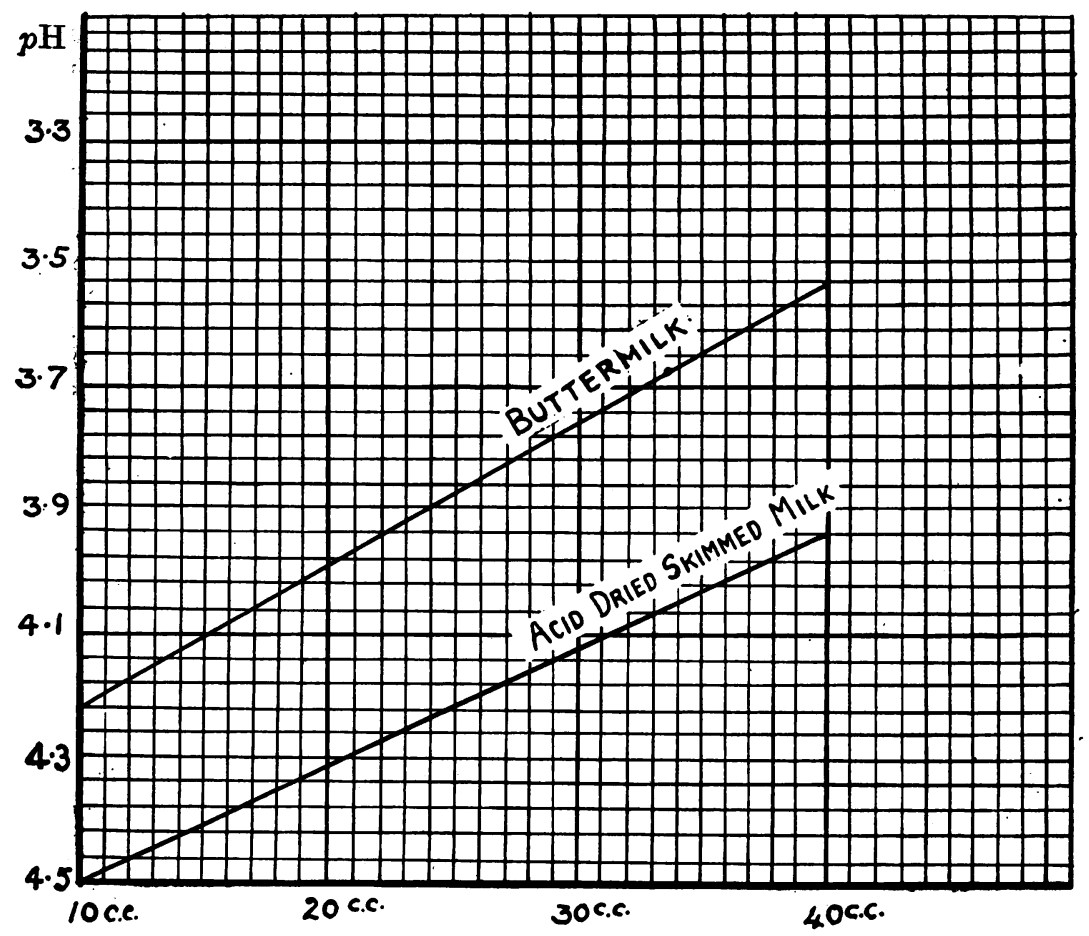

N/10 HCl. per 100 c.c. of Milk Mixture.

The results as portrayed above will be seen to run practically parallel in the two series.

Summary and Conclusions.-The use of an acid dried skimmed milk mixture as a substitute for buttermilk is discussed. The preparation of the acid dried milk mixture suggested can easily be carried out in the poorest home and by the least intelligent person. Lactic acid in the proportion of 0.7 per cent. (one drachm to the pint) is added to the amount of water requisite for reconstituting the milk powder. This is brought to the boil and then mixed directly with the powder, stirring the while. A fine flocculent curd results, in which it is found no clotting takes place on the addition of rennin.

The percentage composition of this mixture differs little from that of buttermilk itself, and is suitable for use in cases of gastro-intestinal disturbance and acute gastro-enteritis. 
A series of experiments has been carried out and shows that the hydrogen ion concentration and buffer values of this preparation are similar to those of buttermilk.

This acid dried skimmed milk mixture is therefore recommended as being suitable for use in all those cases in which buttermilk itself has proved of value, and can, in fact, be regarded as a suitable and efficient substitute.

\section{REFERENCES.}

1. Faber, H. K., Amer. J. Dis. Child., Chic., 1926, XXXI, 395.

2. Levine, V. E., Arch. Ped., N.Y., 1926, XLIII, 631.

3. Marriott, W. M., and Davidson, L. T., Amer. J. Dis. Child., Chic., 1923, XXVI, 542.

4. Schiff, E., and Mosse, K., Saure Milchmischungen in der Ernährungtherapie des Säuglings, Berlin, 1924.

5. Brahdy, N. B., Amer. J. Dis. Child., Chic., 1927, XXXIII, 451.

6. Powers, H. G., ibid., 1925, XXX, 454.

7. Thomson, J., The Clinical Study and Treatment of Sick Children, Edin., 1925, 168.

8. Finkelstein, H., Lehrbuch der Sáuglingskrankheiten, Berlin, 1924, 101.

9. Clark, W. M., The Determination of Hydrogen Ions, Baltimore, 1922, 128-31.

10. Gillespie, L. J., Soil Science, New Brunswick,1920, IX, 115. Gillespie, L. J., J. Amer. Chem. Soc., Pa., 1920, XLII, 742. 